\title{
Derleme
}

\section{Diyabetik maküler ödemde görüntüleme}

\author{
Çağrı İlhan \\ Göz Hastalıkları Kliniği, Hatay Devlet Hastanesi, Hatay, Türkiye.
}

\section{Öz}

Diyabetik maküler ödem (DMÖ), diyabetik retinopatinin görme kaybı ile sonuçlanan en önemli komplikasyonlarından biridir. Dünya genelinde, yılda 100.000'den fazla olguda yasal körlüğe neden olduğu bilinmektedir. Bu bakımdan ele alındığında hastalık ciddi bir halk sağlığı sorunudur. DMÖ tanısında standardizasyonun sağlanması, doğru olgularda tedavi kararı verilmesi hasta kayıtlarında ortak bir dil kullanılması açısından gereklidir. Early Treatment Diabetic Retinopathy Study (ETDRS) Grubu'nun önerdiği tanı kriterleri, gelișen görüntüleme yöntemlerinin katkısı ve hastalık hakkındaki bilgilerimizin daha ilerilere taşınması nedeniyle, bugün için önemini büyük ölçüde yitirmiştir. Oftalmolojideki teknik gelişmelere paralel, DMÖ tanı ve takibinde kullanılan yöntemlerdeki gelişim süreklilik arz etmektedir. Fundus biyomikroskopisi, renkli fundus fotoğraflaması, fundus floresein anjiografi ve optik koherans tomografi (OKT) klinik pratiğimizde en sık kullandığımız ve gelenekselleşmiş yöntemlerdir. Fundus otofloresans, mikroperimetri, tarayıcı laser oftalmoskopi ve OKT ile ölçülen retinal kalınlık haritalamaları yeni yöntemler olmamalarına rağmen, ilave özelliklerle DMÖ tanı ve takibinde kendilerine kullanım alanı bulan geleneksel yöntemlerin yeniden yorumlanmış halleri sayılabilir. Yeni yazılım ve donanım eklentileri ile zenginleştirilen polarizasyon duyarlı OKT, en face OKT, OKT anjiografi ve adaptif optik görüntüleme ise muhtemelen DMÖ tanı ve takibinde gelecekte daha çok kullanılacak olan yeni görüntüleme yöntemleridir. Gerek mevcut az kullanılan yöntemlerin DMÖ'deki kullanım alanının genişlemesi gerek tanımlanmış yeni yöntemler, DMÖ ile ilgili bilgilerimizi artırmamız ve daha etkin tedavi sağlamamıza katkıda bulunacaktır. Bu çalışmada amacımız, DMÖ tanı ve takibinde kullanılan geleneksel yöntemler, ilave modifikasyonlarla kullanılmaya başlanmış yöntemler ve yeni görüntüleme yöntemleri hakkında bilgi vermektir.

Anahtar sözcükler: Diyabetik maküler ödem, fundus floresein anjiografi, optik koherans tomografi, fundus otofloresans, mikroperimetri, tarayıcı laser oftalmoskopi

\section{The imaging methods in diabetic macular edema}

\begin{abstract}
Diabetic macular edema (DME) is one of the most important complications of diabetic retinopathy. Globally, it is known that over 100.000 cases per year cause legal blindness. In this regard, the disease is a serious public health issue. Standardization of diagnosis of DME is a necessecity in order to initiate the treatment for the respective cases and to use a common language in medical records.
\end{abstract}

Yazının geliş tarihi: 25.01.2018 Yazının kabul tarihi: 02.10.2018

Sorumlu Yazar: Çağrı İlhan, Merkez Mah. Tayfur Sokmen Cad. No:36, 31080, Antakya/Hatay. E-posta: cagriilhan@yahoo.com, Tel: 05331339709 
Diagnosis criteria of Early Treatment Diabetic Retinopathy Study (ETDRS) Group have mostly lost its value as the recent developments in the imaging modalities improve our knowledge behind this disorder. Parallel to the technical developments in ophthalmology, the methodological development in the diagnosis and follow-up of DME is also continuous. Fundus biomicroscopy, colored fundus photography, fundus fluorescein angiography, and optical coherence tomography (OCT) are most commonly used conventional methods in clinical practice. Fundus autofluorescence, microperimetry, scanning laser ophthalmoscopy, and retinal thickness mapping by OCT are not new methods, but they are considered as reviewed techniques with additional features used in diagnosis and follow-up of DME. Polarization sensitive OCT, en face OCT, OCT angiography, and adaptive optic imaging developed with new softwares and hardwares are new imaging methods that probably will be more commonly used in the future of the DME diagnosis and follow up. Expanding the use of less used methods and new techniques will increase our knowledge about diabetic macular edema and will help to treat it more effectively. In this study our goal is to give information about conventional imaging methods, imaging methods used after additional modifications, and new imaging methods used in diagnosis and follow up of DME.

Keywords: Diabetic macular edema, fundus fluorescein angiography, optic coherence tomography, fundus autofluorescence, microperimetry, scanning laser ophthalmoscopy

\section{Giriş}

Diyabetik retinopatinin görme kaybına neden olan birçok komplikasyonu olmasına rağmen diyabetik maküler ödem (DMÖ) bunların içinde en önemlisidir. Plevelansı, herhangi bir evredeki diyabetik retinopatili olgularda \%12 olan DMÖ'nün, dünyada yılda 100.000 'den fazla olguda yasal körlüğe neden olduğu bilinmektedir.1,2 Diyabetin süresi, HbA1c yüksekliği, cinsiyet, diüretik kullanımı, kardiyovasküler hastalıkların varlığı ve proteinüri DMÖ gelişimindeki sistemik risk faktörleridir. ${ }^{3}$ Kronik hiperglisemi, hiperkolesterolemi, ileri glikasyon son ürünleri, serbest oksijen radikalleri ve protein kinaz $\mathrm{C}$ aktivasyonu vasküler endotelyal growth factor (VEGF) düzeylerini artırır. ${ }^{4}$ DMÖ patogenezine katkıda bulunan birçok yolak içinde en iyi açıklanmış olanı ve hakkında en fazla çalışma bulunanı VEGF yolağıdır. VEGF aracilığıyla inflamatuar hücre göçü ve adezyonu artar. Lökositler endotel disfonksiyonuna neden olur ve iç kan-retina bariyeri bozulur. Böylece biriken intraretinal ve subretinal sivi, makula yapısını ve fonksiyonunu bozar.5-8 Makulada yoğun bulunan ve oblik seyreden müller hücrelerinin şişerek hasar görmesi ve eksternal limitan membrandaki sıkı okludin bağlantının kaybı da kistoid forma dönüşüme katkı sağlar. ${ }^{9}$ DMÖ tanısında yaygın ortak bir dil kullanılması, tedavi ihtiyacı olan doğru olguların etkin tedavi edilmesini ve doğru dokümantasyonu sağlar. Geçmişte bu amaçla kullanılan Early Treatment Diabetic Retinopathy Study (ETDRS) kriterleri, gelişen görüntüleme yöntemlerinin katkısı ve hastalık hakkındaki bilgilerimizin artmasıyla, bugün için kullanılabilir olma özelliğinde değildir. $\mathrm{Bu}$ derleme çalışmasında, geleneksel (konvansiyonel) yöntemler, geleneksel yöntemlerin farklı yorumları ve yeni yöntemlerin DMÖ tanı ve takibindeki klinik kullanım sahalarının neler olabileceğinden bahsedilmiștir. Tablo 1'de bu görüntüleme yöntemlerinin neler olduğu kısaca özetlenmiştir.

Diyabetik maküler ödemde geleneksel görüntüleme yöntemleri

Fundus biyomikroskopisi ve renkli fundus fotoğrafı DMÖ tanısında birinci basamak yöntemdir ve yıllarca altın standart olarak kullanılmıştır. Fundus biyomikroskopisi kontakt ve kontakt olmayan yöntemle uygulanabilir. Kontakt fundus biyomikroskopisi daha sensitif bir görüntüleme yöntemdir ve arka kutbun yanı sira indentasyon ile perifer retinada daha geniş bir alanın görüntülenmesini sağlar. Kontakt olmayan fundus biyomikroskopisi ise korneaya temas olmaması bakımından hasta açısından daha konforlu ve hekim açısından da kolay bir görüntüleme 
yöntemidir. Nitekim biyomikroskopisinden kontakt daha fundus kullanılmaktadır ve bakımından kontakt yakındır. ${ }^{10}$

görüntü kalitesi yönteme çok

Tablo 1. Diyabetik maküler ödemde görüntüleme yöntemleri

$$
\begin{aligned}
& \text { Geleneksel Görüntüleme Yöntemleri } \\
& \text { •Kontakt/kontakt olmayan fundus } \\
& \text { biyomikroskopisi } \\
& \text { •Renkli fundus fotoğraflaması } \\
& \text { •Fundus floresein anjiografi } \\
& \text { •Optik koherans tomografi (SD-OKT) } \\
& \text { Geleneneksel Görüntüleme Yöntemlerinin } \\
& \text { Yeniden Yorumlanması } \\
& \text { •Fundus otofloresans } \\
& \text { •Mikroperimetri } \\
& \text { •Tarayıcı laser oftalmoskopi } \\
& \text { •OKT ile retinal kalınlık haritalaması } \\
& \text { Yeni Görüntüleme Yöntemleri } \\
& \text { •Polarizasyon duyarlı OKT } \\
& \text { •En face OKT } \\
& \text { •OKT anjiografi } \\
& \text { •Adaptif optik }
\end{aligned}
$$

ETDRS Grubu, 1991 yılinda, diyabetik retinopati (DR) olgularının fotoğraflamasında standardı sağlamak amacıyla her biri 30 derecelik bir alanı kapsayan 7 fotoğrafik alan tanımlamıştır ki bunlar optik disk, makula, 4 major vasküler arkad ve makula temporalini içermektedir. Aynı grup tarafından, makula merkezli 3 konsantrik halka içeren 9 ETDRS grid alanı da tanımlanmıştır ki bunlar DMÖ olgularının dökümantasyonunda daha işlevseldir. ${ }^{11}$ Söz konusu fotoğrafik ve grid ETDRS alanları Şekil 1'de gösterilmiştir. ETDRS Grubu tarafından 1987'de tanımlanan "klinik anlamlı maküler ödem" tanımı fundus biyomikroskopisi ve renkli fundus fotoğraflamasına dayanmaktaydı fakat optik koherans tomografi (OKT) çağında bu tanımlama önemli ölçüde değerini yitirmiş durumdadır. ${ }^{12}$
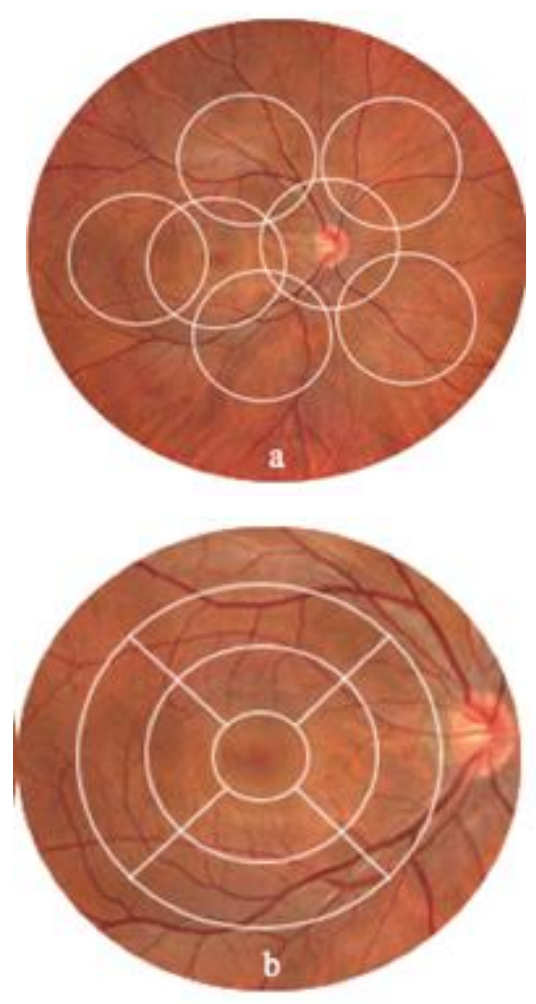

Şekil 1. Early Treatment Diabetic Retinopathy Study (ETDRS) Grubu tarafından tanımlanan fotoğrafik ve grid alanlar. a) 7 fotoğrafik alan, b) makula merkezli 9 grid alan.

Fundus floresein anjiografi (FFA), retinal damarlardaki sıvı dinamiğini ve retinanın perfüzyonunu gösteren bir görüntüleme yöntemidir. Haricen verilen maddenin retinal ve koroidal damarlardan geçerkenki floresans özelliği sayesinde birçok retinal hastalığın tanı ve takibinde sıklıkla kullanılmaktadır. FFA erken fazında (yaklaşık 30. sn) floresein perifoveal kapillerlerden geçer. Erken fazda DMÖ olgularında değişken derecelerde kapiller nonperfüzyon ve hipofloresan alanlar görülebilir. Geç fazda ise (yaklaşık 9. dk) fokal veya diffüz floresein sızıntısı varlığı ile FFA'daki klasik "taç yaprağı" paternindeki hiperfloresans oluşmaktadır.13 FFA günümüz pratiğimizde, anti-VEGF ilaç raporu oluşturulmadan önce yapılması gereken standart tanı yöntemi olarak, hala çok önemlidir.

Optik koherans tomografi kisaca makulanın sanal optik biyopsisini sağlayan bir görüntüleme yöntem olarak değerlendirilebilir. Yakın infrared ışığın 
düşük koherans inferometrisini kullanarak retina, koroid, ön segment, optik sinir başı ve retina sinir lifi tabakasinın kesitsel görüntülerini oluşturmaktadır. ${ }^{14} 2004$ yılından bu yana sıklıkla kullanılan spektral domain OKT (SD-OKT) yüksek çözünürlüklü görüntü sağlamaktadır. DMÖ olgularında intraretinal sıvı birikimi sonucu oluşan retinal kalınlaşma, OKT'de intraretinal kistoid boşluklar veya subretinal sıvı paketlerine bağlı foveal depresyon azalması veya kaybı olarak görülür. Bazı olgularda subretinal sıvı nörosensöryel retina dekolmanına yol açabilir. Uzun dönem sebat etmiş DMÖ olgularında, retinal mimarinin bozulmasına bağlı, OKT'de görülmesi gereken hiporeflektif veya hiperreflektif bantlar kaybolabilir. ${ }^{13}$ OKT retinanın fonksiyonel anatomisiyle ilgili bilgi vermesi bakımından benzersiz bir yöntemdir. Klinik kullanıma girmesinden sonra OKT, DMÖ tanısında baskın yöntem olmuştur ve çeşitli yazarlar tarafından bu yöntem standardize edilmeye çalışılmıştır. Buna göre DMÖ olgularında OKT ile değerlendirilen 5 temel parametre şunlardır: Retinal kalınlık, retinal morfoloji (intraretinal kist varlığı), retinal topografi, vitreoretinal ara yüzey özellikleri ve eksternal limitan membran ve iç segment-dış segment (ISOS) bandının yapısal bütünlüğü. Şekil 2, Sikorski ve ark. 15 tarafından önerilen OKT temelli DMÖ sınıflamasını göstermektedir.

\section{Diyabetik maküler ödemde geleneksel görüntüleme yöntemlerinin yeniden yorumlanması}

Fundus otofloresans (FAF), arka segmentteki otofloresans özelliği olan maddelerin konfokal tarayıcı laser oftalmoskop veya modifiye fundus kameraları ile görüntülenmesi yöntemidir. Retina pigment epitelinin sağlamlığını gösterir ve yaşa bağlı makula dejenerasyonunda sıklıkla kullanılmaktadır. Yoshitake ve ark. 16 DMÖ ve kontrol grubunda FAF sinyal yoğunluğunu incelemişlerdir. Bu çalışmanın sonuçlarına göre santral alanda tüm olgularda düşük FAF sinyal yoğunluğu olduğu, buna ilaveten DMÖ olgularında parafoveal kadranlarda da düşük sinyal yoğunluğu olduğu gözlenmiştir. Aynı çalışmada bu farklılığın DMÖ tanısında kullanılabileceği bildirilmiştir. Bir başka çalışma ise DMÖ olgularında FAF bulgularını çok daha ayrıntılı yorumlamış ve normal FAF bulgularının $\mathrm{da}$ olabileceğine ilaveten kistoid hiperotofloresans, irregüler hipootofloresans ve spot hiperotofloresans paternlerini tanımlamıştır. ${ }^{17}$

Mikroperimetri, retinal patolojiler ile fonksiyonel kayıplar arasındaki topografik ilişkiyi gözler önüne seren bir görüntüleme yöntemi olmasına rağmen kendisine geniş bir kullanım alanı yaratamamıștır. $\mathrm{Bu}$ yöntemde retinal duyarlılıktaki azalmalar kırmızı gibi sıcak renklerle gösterilirken, yeșil renk normal retinal hassasiyeti, mavi de fiksasyonu ifade eder. Mikroperimetri maküler duyarlılığı yansitması ve ekstrafoveal fiksasyonu göstermesi bakımından DMÖ tanı ve takibinde kullanılabilecek hassas yöntemlerden biridir. ${ }^{18}$

Tarayıcı laser oftalmoskopi, seçili retinal alana farklı şekil, boyut ve yoğunluklarda görsel uyarılar vererek, fundusun eş zamanlı muayenesine imkân sağlayan bir yöntemdir.19 Özellikle retro modda intraretinal kistlerin topografik yerleşimini ve büyüklügünü en iyi gösteren yöntemlerden biri tarayıcl laser oftalmoskopidir. Vujosevic ve ark.20 nın DMÖ tanısında tarayıcı laser oftalmoskopi uygulamasının sonuçlarını inceledikleri çalışmalarında bu yöntemin OKT, FAF ve FFA kadar sensitif ve spesifik oldukları bildirilmiștir. FFA ile klyaslandığında, girişim gerektirmemesi en önemli avantajıdır.

Spektral domain OKT, hayali retinal kesitler oluşturmasının yanı sıra, retinal kalınlık haritasını nicel ölçümler şeklinde vermekte ve renklendirme yapmaktadır. Danis ve Hubbard ${ }^{13}$ yaptıkları bir çalışmada, retinal kalınlık haritasının kullanılmasının DMÖ tanı ve takibinde yardımcı olabileceğini belirtmişlerdir. 


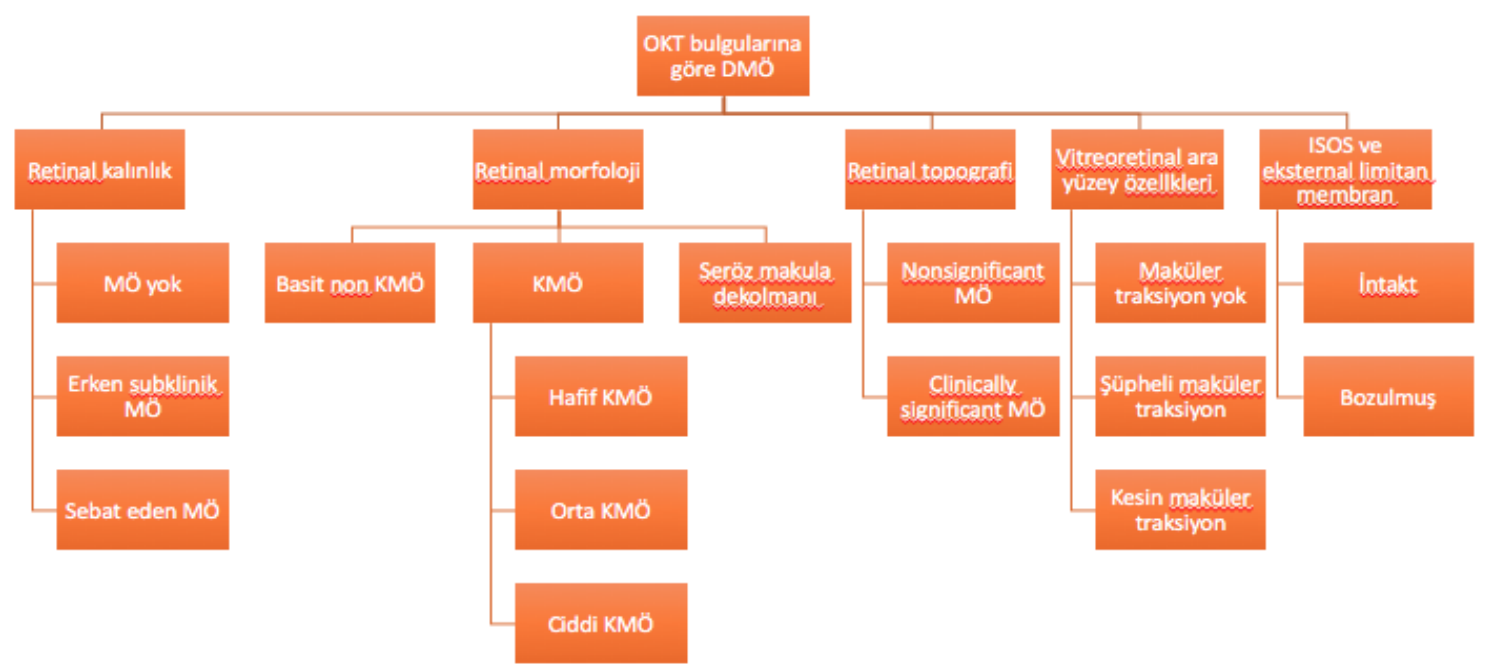

Şekil 2: Sikorski ve ark. (2013) tarafından önerilen optik koherans tomografi temelli diyabetik maküler ödem sınıflaması. OKT: Optik koherans tomografi, MÖ: Maküler ödem, KMÖ: Kistoid maküler ödem, ISOS: İçsegment- dış segment bandı.

\section{Diyabetik maküler ödemde yeni görüntüleme yöntemleri}

Polarizasyon duyarlı OKT, dokunun polarizasyon farklılı̆̆ı özelliğini kullanarak 3 boyutlu haritalama yapan, yeni bir yöntemdir. Sert eksudaların yaygınlık ve yerleşimini geleneksel renkli fundus fotoğraflarına göre daha doğru şekilde saptaması bakımından, DMÖ tanı ve takibinde kullanılabileceği belirtilmiştir. ${ }^{21}$

En face OKT, yeni bir yazılım eklentisi ile koronal planda C-scan görüntüler sağlamaktadır. En face OKT'de sert eksudalar hiperrefleksitf spotlar şeklinde görülmektedir. SD-OKT ile karşılaştırıldığında, en face OKT, eksudaların yeri ve büyüklügü hakkından daha fazla bilgi sağlamaktadır. ${ }^{18}$

OKT anjiografi, FFA ile kıyaslandığında girişimsel olmayan, güvenli ve hızlı bir yöntemdir. Mikroanevrizma, vasküler lup, nonperfüzyon, neovaskülarizasyon, foveal avasküler zonda erozyon, venöz boncuklanma ve kapiller yatak ile ilgili çok daha fazla detay sağlamaktadır. Ayrıca santral retinal iskemi ve remodellingi gösteren kantitatif ölçüm yapması bakımından benzersizdir. Lee ve Rosen (2016) gerçekleştirdikleri OKT anjiografi çalışmalarında, foveal avasküler zon çapı, asirkülarite indeksi ve axis ratio gibi hesaplamaların DMÖ tanı ve takibinde faydalı olduğunu bildirmiştir. ${ }^{22}$

Adaptif optik, aberasyonları düzelterek fundus kamera ile parafoveal konların yüksek çözünürlüklü görüntülemesini sağlamaktadır. $\mathrm{Bu}$ teknolojinin uygulandığı bir çalışmada DMÖ'e bağlı olarak $\mathrm{mm}^{2}$ başına düşen kon yoğunluğunda anlamlı azalma olduğu gösterilmiştir. ${ }^{23}$ Adaptif optik oftalmolojide yeni kullanılmaya başlanan bir yöntemdir ve kullanımı yakın gelecekte artacak gibi görünmektedir.

\section{Sonuç}

Sonuç olarak, oftalmolojideki teknik gelişmelere paralel, DMÖ tanı ve takibinde kullanılan yöntemler her geçen gün güncellenmekte ve standardizasyonlar önerilmektedir. $\mathrm{Bu}$ yöntemler bugün için fundus biyomikroskopisi, renkli fundus fotoğraflaması, FFA ve OKT'nin içinde bulunduğu geleneksel yöntemler, fundus otofloresans, mikroperimetri, tarayıcı laser oftalmoskopi ve retinal kalınlık haritalamasının yapıldığı geleneksel yöntemlerin yeniden yorumlanmış halleri ve polarizasyon duyarlı OKT, en face OKT, OKT anjiografi ve adaptif optik görüntülemenin içinde bulunduğu yeni görüntüleme yöntemleri olarak sinıflandırılabilir. 


\section{Kaynaklar}

1. Klein R., Knudtson

M.D., Lee K.E., Gangnon R., Klein $\quad$ B. The Wisconsin Epidemiologic Study of Diabetic Retinopathy: XXII the twentyfive-year progression of retinopathy in persons with type 1 diabetes. Ophthalmology. 2008;115(11):18591868.

2. Paulus Y.M., Gariano R.F. Diabetic retinopathy: a growing concern in an aging population. Geriatrics. 2009;64(2):16-20.

3. White N.H., Sun W., Cleary P.A., Tamborlane W.V., Danis R.P., Hainsworth D.P., Davis M.D. DCCT-EDIC Research Group. Effect of prior intensive therapy in type 1 diabetes on 10-year progression of retinopathy in the DCCT/EDIC: comparison of adults and adolescents.

Diabetes. 2010;59(5):1244-1253.

4. Bhagat N., Grigorian R.A., Tutela A., Zarbin M.A. Diabetic macular edema: pathogenesis and treatment. Surv Ophthalmol. 2009;54(1):1-32.

5. Zhang X., Bao S., Lai D., Rapkins R.W., Gillies M.C. Intravitreal triamcinolone acetonide inhibits breakdown of the blood-retinal barrier through differential regulation of VEGF-A and its receptors in early diabetic rat retinas. Diabetes. 2008;57(4):1026-1033.

6. Leal E.C., Manivannan A., Hosoya K., Terasaki T., Cunha-Vaz J., Ambrosio A.F., Forrester J.V. Inducible nitric oxide synthase isoform is a key mediator of leukostasis and blood-retinal barrier breakdown in diabetic retinopathy. Invest Ophthalmol Vis Sci. 2007;48(11):5257-1565.

7. Zhang X., Zeng H., Bao S., Wang N., Gillies M.C. Diabetic macular edema: new concepts in patho-physiology and treatment. Cell Biosci. 2014;14;4:27.

8. Park H.Y., Kim J.H., Park C.K. Neuronal cell death in the inner retina and the influence of vascular endothelial growth factor inhibition in a diabetic rat model. $A m \quad J$ Pathol. 2014;184(6):1752-1762.

9. Omri S., Omri B., Savoldelli M., Jonet L., Thillaye-Goldenberg B., Thuret G., Gain
P., Jeanny J.C., Crisanti P., Behar-Cohen F. The outer limiting membrane (OLM) revisited: clinical implications. Clin Ophthalmol. 2010 Apr 26;4:183-195.

10. Mackenzie S., Schmermer C., Charnley A., Sim D., Vikas Tah, Dumskiyj M., Nussey S., Egan C. SDOCT imaging to identify macular pathology in patients diagnosed with diabetic maculopathy by a digital photographic retinal screening programme. PLoS One. 2011;6(5):e14811.

11. Early Treatment Diabetic Retinopathy Study Research Group.

Grading diabetic retinopathy from stereoscopic color fundus photographs-an extension of the modified Airlie House classification. ETDRS report number 10. Ophthalmology. 1991;98(5 Suppl):786-806.

12. Huang D., Swanson E.A., Lin C.P., Schuman J.S., Stinson W.G., Chang W., Hee M.R., Flotte T., Gregory K., Puliafi to C.A., and Fujimoto J.G. Optical coherence tomography. Science 1991;254(5035):1178-81.

13. Danis R.P., Hubbard L.D. Imaging of diabetic retinopathy and diabetic macular edema. Curr Diab Rep. 2011;11(4):236-243.

14. Çıtırık M., İlhan Ç., Teke M.Y. Optik Koherans Tomography. Güncel Retina. 2017;1(1):58-68.

15. Sikorski B.L., Malukiewicz G., Stafiej J., Lesiewska-Junk H., Raczynska D. The diagnostic function of OCT in diabetic maculopathy. Mediators Inflamm. 2013;2013:434560.

16. Yoshitake S., Murakami T., Uji A., Unoki N., Dodo Y., Horli T., Yoshimura N. Clinical relevance of quantified fundus autofluorescence in diabetic macular oedema. Eye (Lond). 2015;29(5):662669.

17. Shen Y., Xu X., Liu K. Fundus autofluorescence characteristics in patients with diabetic macular edema. Chin Med J (Engl). 2014;127(8):14231428.

18. Midena E., Bini S. Multimodal retinal imaging of diabetic macular edema: toward new paradigms of 
pathophysiology. Graefes Arch Clin Exp Ophthalmol. 2016;254(9):1661-1668.

19. Midena E., Vujosevic S. Microperimetry in diabetic retinopathy. Saudi J Ophthalmol. 2011;25(2):131135.

20. Vujosevic S., Trento B., Bottega E., Urban F., Pilotto E., Midena E. Scanning laser ophthalmoscopy in the retromode in diabetic macular oedema. Acta Ophthalmol. 2012;90(5):374-380.

21. Lammer J., Bolz M., Baumann B., Pircher M., Gerendas B., Schlanitz F., Hitzenberger C.K., Schmidt-Erfurth U. Detection and analysis of hard exudates by polarization-sensitive optical coherence tomography in patients with diabetic maculopathy. Invest Ophthalmol Vis Sci. 2014;55(3):15641571.

22. Lee J., Rosen R. Optical Coherence Tomography Angiography in Diabetes. Curr Diab Rep. 2016;16(12):123.

23. Soliman M.K., Sadiq M.A., Agarwal A., Sarwar S., Hassan M., Hanout M., Graf F., High R., Do D.V., Nguyen Q.D., Sepah Y.J. High-Resolution Imaging of Parafoveal Cones in Different Stages of Diabetic Retinopathy Using Adaptive Optics Fundus Camera. PLoS One. 2016;11(4): $\mathrm{e} 0152788$. 